\title{
Necrotrophic Fungus Pyrenophora tritici-repentis Triggers Expression of Multiple Resistance Components in Resistant and Susceptible Wheat Cultivars
}

\author{
Ethan J. Andersen ${ }^{1}$, Madhav P. Nepal (D) ${ }^{2 *}$, and Shaukat $\mathrm{Ali}^{3}$ \\ ${ }^{1}$ Department of Biology, Francis Marion University, Florence, SC 29506, USA \\ ${ }^{2}$ Department of Biology and Microbiology, South Dakota State University, Brookings, SD 57007, USA \\ ${ }^{3}$ Department of Agronomy, Horticulture and Plant Science, South Dakota State University, Brookings, SD 57007, USA
}

(Received on June 22, 2020; Revised on January 16, 2021; Accepted on January 25, 2021)

Tan spot of wheat, caused by Pyrenophora tritici-repentis (Ptr), results in a yield loss through chlorosis and necrosis of healthy leaf tissue. The major objective of this study was to compare gene expression in resistant and susceptible wheat cultivars after infection with Ptr ToxA-producing race 2 and direct infiltration with Ptr ToxA proteins. Greenhouse experiments included exposure of the wheat cultivars to pathogen inoculum or direct infiltration of leaf tissue with Ptr-ToxA protein isolate. Samples from the experiments were subjected to RNA sequencing. Results showed that ToxA RNA sequences were first detected in samples collected eight hours after treatments indicating that upon Ptr contact with wheat tissue, Ptr started expressing ToxA. The resistant wheat cultivar, in response to Ptr inoculum, expressed genes associated with plant resistance responses that were not expressed in the susceptible cultivar; genes of interest included five chitinases, eight transporters, five pathogen-detecting receptors, and multiple classes of signaling factors. Resistant and susceptible wheat cultivars therefore differed in their response in the expression of genes that encode chitinases, transporters, wall-associated kinases, permeases, and wound-induced proteins, among others. Plants

\footnotetext{
*Corresponding author.

Phone) +1-605-688-5971, FAX) +1-605-688-6677

E-mail)madhav.nepal@sdstate.edu

ORCID

Madhav P. Nepal

https://orcid.org/0000-0001-5565-523X

(c) This is an Open Access article distributed under the terms of the Creative Commons Attribution Non-Commercial License (http:// creativecommons.org/licenses/by-nc/4.0) which permits unrestricted noncommercial use, distribution, and reproduction in any medium, provided the original work is properly cited.
}

Articles can be freely viewed online at www.ppjonline.org. exposed to Ptr inoculum expressed transcription factors, kinases, receptors, and peroxidases, which are not expressed as highly in the control samples or samples infiltrated with ToxA. Several of the differentially expressed genes between cultivars were found in the Ptr resistance QTLs on chromosomes 1A, 2D, 3B, and 5A. Future studies should elucidate the specific roles these genes play in the wheat response to Ptr.

Keywords : pathogen resistance, plant-pathogen interaction, Pyrenophora tritici-repentis, RNA-seq, tan spot, wheat

Handling Editor : Cecile Segonzac

Pathogenic fungi negatively impact crop production through qualitative and quantitative reduction in yield, through mycotoxin production and tissue necrosis (Singh et al., 2016). Necrotic leaf spotting diseases are especially damaging to wheat crops (Singh et al., 2016), causing leaf tissue death, reducing photosynthetic capacity and carbohydrate production. Wheat supplies a large portion of the calories for human nutrition (Food and Agriculture Organization of the United Nations, 2013), and fungal pathogens like Pyrenophora tritici-repentis (Ptr) cause some of the most devastating yield-limiting crop diseases (Murray et al., 2015). Tan spot (TS) of wheat is caused by Ptr and results in up to 50\% yield loss in wheat (Rees and Platz, 1983). Pathogens like Ptr have evolved ways to hijack plant resistance signaling pathways, facilitating their infection and reproduction (Shi et al., 2016). Ptr possesses a unique repertoire of toxins (namely Ptr ToxA, Ptr ToxB, and Ptr ToxC) that rely on host susceptibility genes for infection (Faris et al., 2013). Ptr ToxA moves into wheat mesophyll cells to disrupt chloroplast activity and Ptr ToxB acts extracellularly (Figueroa et al., 2015). Recognized by 
brown necrotic lesions surrounded by yellow chlorotic halos as symptoms, Ptr overwinters as pseudothecia on wheat residue, dispersal of spores facilitated by wind and periods of prolonged moisture (Ciuffetti and Tuori, 1999). Ptr hostselective toxins (HSTs) cause necrosis and chlorosis in susceptible varieties (Ali and Francl, 2003; Lamari et al., 1998). Variation in Ptr races and wheat cultivar susceptibility has been documented (Ali and Francl, 2003; Lamari et al., 1998), with races of Ptr producing between none and all three toxins and wheat cultivars varying in sensitivity to the toxins. Instead of resistance genes (R genes), wheat variation has been attributed to the presence of susceptibility genes present in many cultivars (Faris et al., 2013). Key details regarding the molecular interactions between HST and wheat proteins have emerged in recent years (Ciuffetti et al., 2010; Faris et al., 2010, 2013; Liu et al., 2017; Manning et al., 2009), stimulating the further elucidation of this host-pathogen interaction.

HSTs are fungal effectors that facilitate infection and access to nutrients. Many HSTs have been identified in species of the Alternaria and Cochliobolus genera, with additional HSTs likely to be found in future research (Petrov et al., 2018). To facilitate infection and nutrient extraction, Ptr produces three HSTs: Ptr ToxA, Ptr ToxB, and Ptr ToxC (Faris et al., 2013). Ptr ToxA causes necrosis in wheat tissue and evidence supports the hypothesis that the Ptr ToxA gene was horizontally transferred from Parastagonospora nodorum, another pathogenic fungus of wheat that causes Septoria/Stagonospora nodorum blotch (Friesen et al., 2006). Ptr ToxA has been shown to move into wheat mesophyll cells, possibly as a homodimer, where it localizes to chloroplasts and binds to the ToxA-binding protein-1 (ToxABP1) and a plastocyanin, leading to chloroplast disruption, production of reactive oxygen species (ROS), and cell death (Manning et al., 2007, 2009; Tai et al., 2007). Ptr ToxA contains an RGD-motif that is involved in targetbinding and movement into wheat mesophyll cells, likely by receptor-mediated endocytosis (Manning et al., 2008). In contrast to Ptr ToxA, Ptr ToxB and Ptr ToxC are both native to Ptr and associated with tissue chlorosis (Ciuffetti et al., 1998). Ptr ToxB acts extracellularly (Figueroa et al., 2015), likely through a ligand-receptor interaction that triggers plant signaling and leads to chlorosis. Ptr ToxC is a small, nonpolar, non-proteinaceous secondary metabolite (Effertz et al., 2002) that has yet to be characterized. Both Ptr ToxA and Ptr ToxB lead to interference with photosynthesis and ROS accumulation, indicating similar mechanisms of action even though they differ in structure (Ciuffetti et al., 2010). Several Ptr races have been identified to possess various combinations of the three toxins, and vari- ous wheat cultivars have shown sensitivity to individual toxin isolates. Integrated disease management of TS may include the use of resistant varieties, fungicide applications, crop rotation, and residue removal to limit overwintering of inoculum (Ciuffetti and Tuori, 1999). Fungicide applications and crop rotations, while effective, are expensive and inconvenient for farmers. Determination of how TS causes disease symptoms, followed by deployment of cultivars with durable resistance will provide an economical solution to yield loss (Rees and Platz, 1983).

The main objective of this study was to compare gene expression of resistant and susceptible wheat cultivars after infection with Ptr ToxA-producing race 2 and direct infiltration with Ptr ToxA. Previous studies assessed gene expression in cultivars after infiltration of Ptr ToxA (Adhikari et al., 2009; Pandelova et al., 2009) and the role of susceptibility gene $T s n 1$, while this study focused on the difference between toxin infiltration and pathogen inoculation regarding the genes involved in defense response. This difference was of interest to us because plant defense responses are not necessarily triggered by pathogenic toxins or effectors, being triggered instead by other pathogenic molecules, such as fungal chitin. Therefore, we assessed the difference in wheat's response to pathogen inoculation and toxin infiltration so as to gain insight into the molecular mechanism. Identification of genes triggered by Ptr HSTs will provide candidates for assessing why some wheat cultivars resist TS symptoms and others develop necrotic lesions. We hypothesize that pathogen inoculation triggers the expression of genes not activated by toxin infiltration, thus exhibiting a difference in defense gene expression between the resistant and susceptible cultivars. These results will impact the development of TS-resistant wheat by informing breeding decisions that ultimately influence farmer variety selection. This will allow us to assess the molecular mechanism that underlies Ptr effectors in wheat cells and understand which signaling mechanism(s) may lead to the disease. Indepth understanding of the molecular basis of the wheatPtr pathosystem will be useful in the development of wheat cultivars that possess durable resistance to Ptr and other necrotic leaf spotting diseases caused by similar pathogens, such as $P$. nodorum.

\section{Materials and Methods}

A workflow diagram outlining the research methodology is shown in Fig. 1 (greenhouse experiments on the left panel, wet lab RNA-sequencing [RNA-seq] work on the upper right and data analysis on the lower right panel). These steps are briefly described below. Transcriptomic data from 
this study were published in BMC Research Note (Andersen et al., 2019b).

Wheat cultivar selection and growth. Two cultivars of wheat were grown, TS resistant Salamouni and TS susceptible Glenlea, selected due to their well-established insensitivity and sensitivity to Ptr ToxA, respectively. Seeds were germinated in petri dishes on damp filter paper and transferred to $3 \times 9 \mathrm{~cm}$ plastic containers (Stuewe \& Sons Inc., Tangent, OR, USA) filled with Sunshine Mix 1 soil (Sun Gro Horticulture, Agawam, MA, USA). Plants were uniformly watered daily with greenhouse conditions of 16-h light and 8 -h dark cycles at $22^{\circ} \mathrm{C}$ for 14 days prior to inoculation/infiltration.

Ptr inoculation and toxin infiltration. Four treatments were used: spray Ptr race 2 inoculum, spray water (control), Ptr ToxA injection, and water injection (control). Inoculum was prepared following methods described in Abdullah et al. (2017). A culture of Ptr race 2 isolate 86-124 was initiated using an agar plug and V8-PDA medium plates (agar $10 \mathrm{~g}$; potato dextrose agar $10 \mathrm{~g} ; \mathrm{CaCO}_{3} 3 \mathrm{~g}$; V8 Juice 150 $\mathrm{ml}$ and $850 \mathrm{ml}$ distilled water) (Lamari and Bernier, 1989). Plates were incubated in darkness for 5 days and colonies were flooded with distilled water and disrupted. Plates were then incubated for $24 \mathrm{~h}$ at $22^{\circ} \mathrm{C}$ in light and then for $24 \mathrm{~h}$ at $16^{\circ} \mathrm{C}$ to cause production of conidia. The spore suspension at 3,000 spores $/ \mathrm{ml}$ was used to inoculate plants with a Preval $\mathrm{CO}_{2}$ pressurized sprayer (http://www.preval. com) (Ali and Francl, 2001; Jordahl and Francl, 1992). A sprayer containing only sterile water was used as a control. Toxin infiltration was accomplished using a $10 \mu \mathrm{g} / \mathrm{ml}$ solution of Ptr ToxA, kindly provided by Dr. Timothy Friesen (USDA-ARS, North Dakota State University), and directly infiltrating leaf tissue using a needle-less syringe (Faris et al., 1996), similarly using sterile water infiltration as a control. Inoculated plants were then placed in an automated humidity chamber at $100 \%$ humidity (misting $16 \mathrm{~s} / 10 \mathrm{~min}$ ). Samples were collected at three timepoints: $0 \mathrm{~h}, 8 \mathrm{~h}$, and $16 \mathrm{~h}$, with two biological replicates for each cultivar, treatment, and timepoint. Liquid nitrogen was used to freeze the samples, stored at $-80^{\circ} \mathrm{C}$ until RNA extraction could be completed.

RNA extraction and sequencing. RNA was extracted using the Ambion PureLink RNA extraction kit (Thermo Fisher Scientific, Waltham, MA, USA) with Trizol reagent. RNA was then purified using DNase to remove any DNA contamination and sequenced at Iowa State University using Illumina HiSEQ 3000 set (Invitrogen, Carlsbad, CA,
USA) at 100 base pairs with single-end reads. Specific sequencing information can be found at the Iowa State University DNA Facility (http://www.dna.iastate.edu/index. $\mathrm{html})$. Resulting data was made available through FASTQ files, which were downloaded from the ISU DNA Facility database.

Data analysis. Resulting FASTQ files were checked for quality using FASTQC (Andrews, 2010), trimmed using Btrim version 0.2.0 (Kong, 2011), and mapped to the International Wheat Genome Sequencing Consortium reference wheat genome IWGSC.41 (International Wheat Genome Sequencing Consortium, 2018) using Hisat version 2.1.0 (Kim et al., 2015) and Htseq with Python (Anders et al., 2015). These programs were locally installed in the South Dakota State University High Performance Computing Cluster and run through a linux terminal. Program default settings were used through the trimming and mapping of the data. Wheat genomic data was accessed from the Ensembl Genomes database (Kersey et al., 2014). The Ptr genome was also accessed from Ensembl Genomes (ASM14998v1.41; Pt-1C-BFP, Pyrenophora triticirepentis Sequencing Project, Broad Institute, http://www. broad.mit.edu) in order to map any pathogen RNA reads that did not map to the wheat genome. The program $\mathrm{R}$ (The R Foundation, 2013) with the Bioconductor package and DESeq2 (Love et al., 2014) were used to assess differential expression of genes between samples through the assembly of count files which were used to create count matrices. Specific raw expression data used are available at the FigShare site (Ptr count data: https://doi.org/10.6084/ m9.figshare.8115989.v3; Wheat count data: https://doi. org/10.6084/m9.figshare.8115992.v3). The DESeq output displayed adjusted $P$-values for comparisons between cultivar, treatment, and timepoint. Genes with adjusted $P$ values less than 0.05 were investigated as differentially expressed genes. Genes differentially expressed between cultivars, treatments, or time points were compiled and assessed based on their sequence annotations and homology in Gene Ontology (GO), InterProScan version 5 (Jones et al., 2014), and BLAST (Altschul et al., 1990), used to predict the general functions and roles in stress response, metabolism, development, and various other cellular processes. The iDEP program was also used to assess differentially expressed genes in wheat tissue (Ge et al., 2018). Differentially expressed gene locations were also compared to known resistance QTLs on wheat chromosomes (Kariyawasam et al., 2016), to assess potential involvement in resistance. Statistics on differentially expressed genes are available in Supplementary Table 1 available at https://doi. 
org/10.6084/m9.figshare.12857594. Our ability to identify specific genes, as significantly differentially expressed and not due to a random variation, was limited by the number of replicates used in this exploratory study. All transcrip-

\section{Experiment}

1. Tan spot susceptible Glenlea and resistant Salamouni wheat germinated for 2 weeks

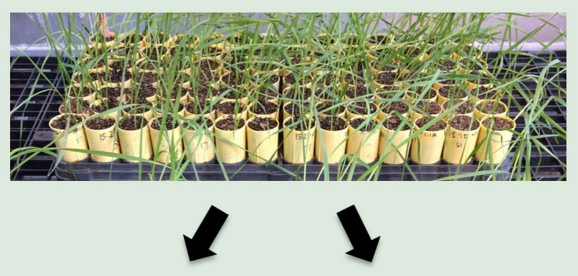

2. Sprayed with Ptr race 2 spores or water (control)

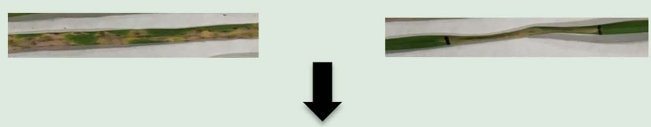

3. Plants transferred to humidity chamber

4. Leaf samples taken at 0,8 , and $16 \mathrm{~h}$

5. Samples collected in tubes and stored in liquid nitrogen until transferred to $-80^{\circ} \mathrm{C}$ tomic data used in this study (raw FASTQ files) were submitted to the Sequence Read Archive (SRA) of the National Center for Biotechnology Information (NCBI) site. These are available under the submission SUB5368694,

\section{RNA extraction}

1. Tissue stored at $-80^{\circ} \mathrm{C}$

2. Tissue disrupted in liquid nitrogen

3. Trizol and Ambion Purelink RNA extraction kit

4. DNase treatment

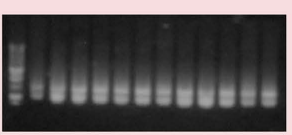

5. Sequencing at lowa State University

\section{Data analysis}

1. FASTQ files received from ISU

2. Quality - FASTQC

3. Filtering/Trimming - Btrim

4. Mapping - Hisat

5. Assembly - Htseq

6. Expression Analysis - DESeq2 (R package)

7. Visualization using iDEP

Fig. 1. Workflow diagram of methods for the tan spot greenhouse RNA sequencing experiment. The experiment was conducted at South Dakota State University Young Brothers Seed Technology Laboratory.

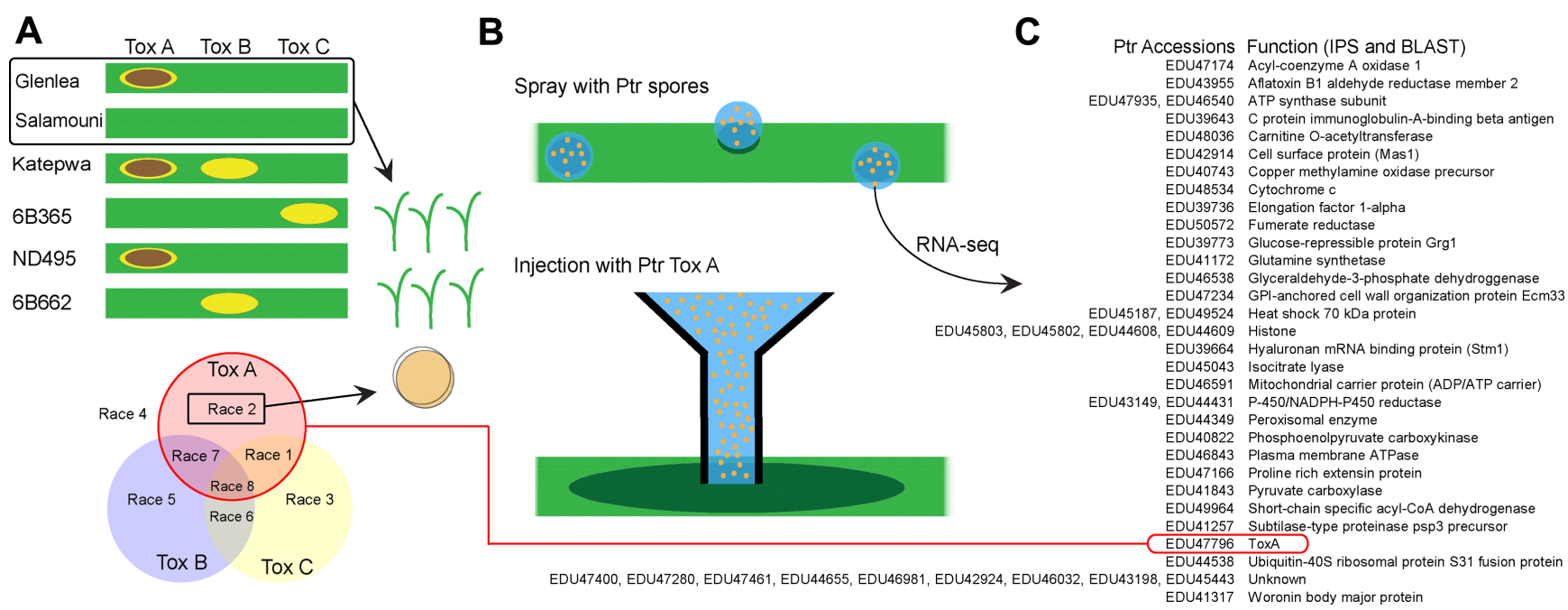

Fig. 2. Experimental design to show that wheat Pyrenophora tritici-repentis (Ptr) genes are expressed upon Ptr exposure. (A) Wheat cultivars and Ptr races possess various susceptibility genes and effectors, respectively. Ptr race 2 resistant and susceptible cultivars were selected to investigate the effect of Ptr ToxA on wheat tissue. (B) Samples were inoculated with Ptr race 2 or infiltrated with ToxA. (C) Ptr genes expressed in inoculation samples across all timepoints included ToxA, a major cause of necrosis, showing that Ptr was expressing ToxA after inoculation. 
Bioproject PRJNA529906 (https://identifiers.org/ncbi/insdc.sra:SRP189899) (Andersen et al., 2019a).

\section{Results}

Differential gene expression. Using the overall workflow shown in Fig. 1, reads from RNA-seq were mapped to the Ptr genome along with the wheat genome. Since reads mapped to the ToxA gene, as well as other Ptr genes in inoculated samples, we can confirm that Ptr produces ToxA in wheat tissue upon the pathogen exposure (Fig. 2A-C). There were 8,760 genes that mapped to the Ptr genome, much fewer than the 77,924 genes that mapped to the wheat genome. Many of the other transcripts found from Ptr (see Fig. 2) do not have a direct role in pathogenesis and are likely involved in general cellular function. ToxA was not expressed in $0 \mathrm{~h}$ samples, with the highest level of expression in a $0 \mathrm{~h}$ sample being 3 read counts. The 8 and $16 \mathrm{~h}$ samples showed ToxA levels between 65 and 356 counts per sample. This indicates that Ptr does not express ToxA until it comes in contact with wheat tissue. No Ptr genes were differentially expressed between the two cultivars, indicating that the difference in disease response may reside mainly in wheat's response to Ptr and not Ptr's response to different cultivars of wheat. Reads mapped to the wheat genome resulted in many differentially expressed
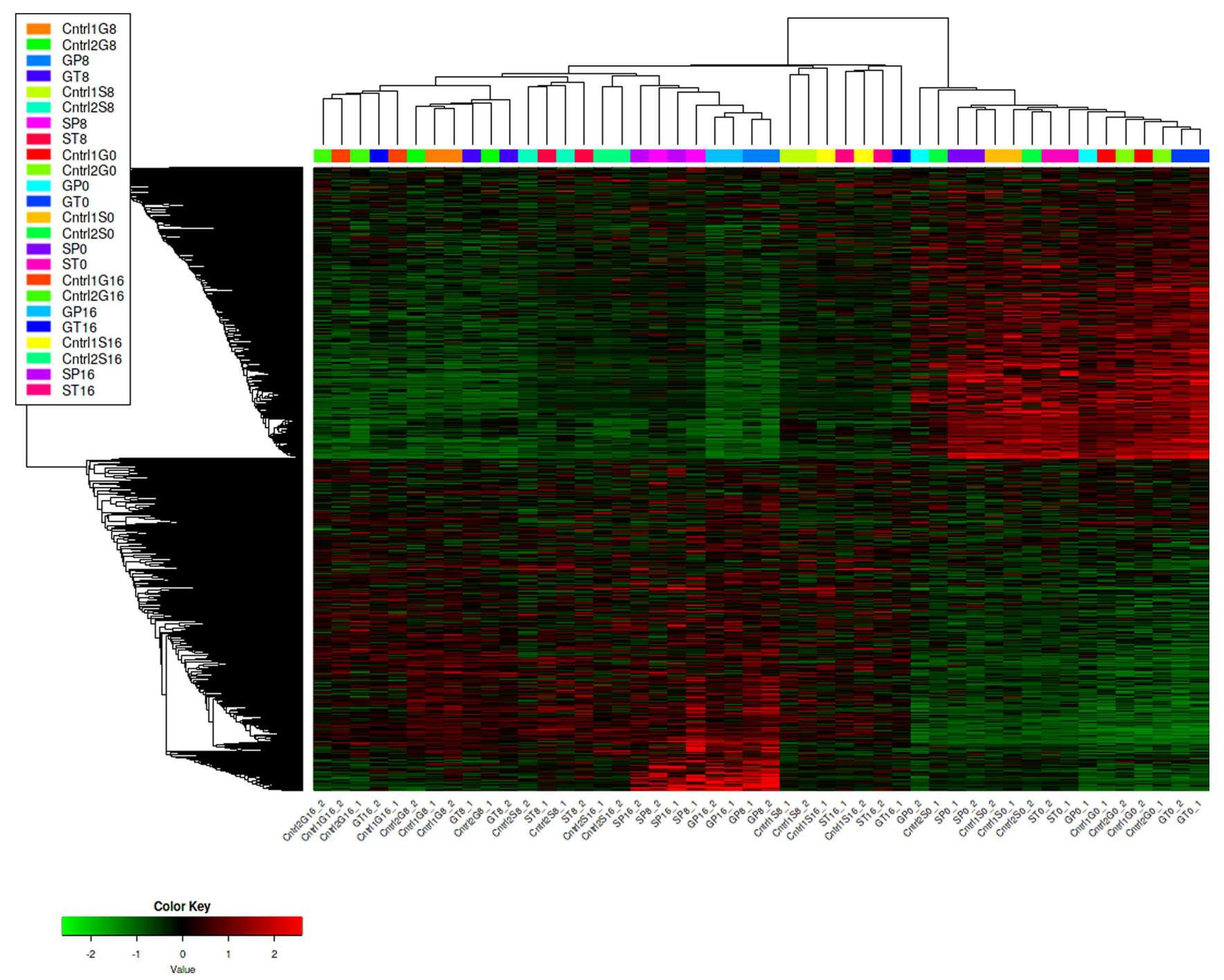

Fig. 3. Heatmap visualization of expression data was constructed using integrated Differential Expression and Pathway analysis (iDEP). Sample names include cultivar ( $\mathrm{G}$ and $\mathrm{S}$ for Glenlea and Salamouni, respectively), treatment (P, T, Cntrl1, Cntrl2 for pathogen inoculation, toxin infiltration, inoculation control, and infiltration control, respectively), and timepoint $(0,8$, and $16 \mathrm{~h})$. Samples that increased or decreased in expression were colored red and green, respectively, with little change shown in black. 

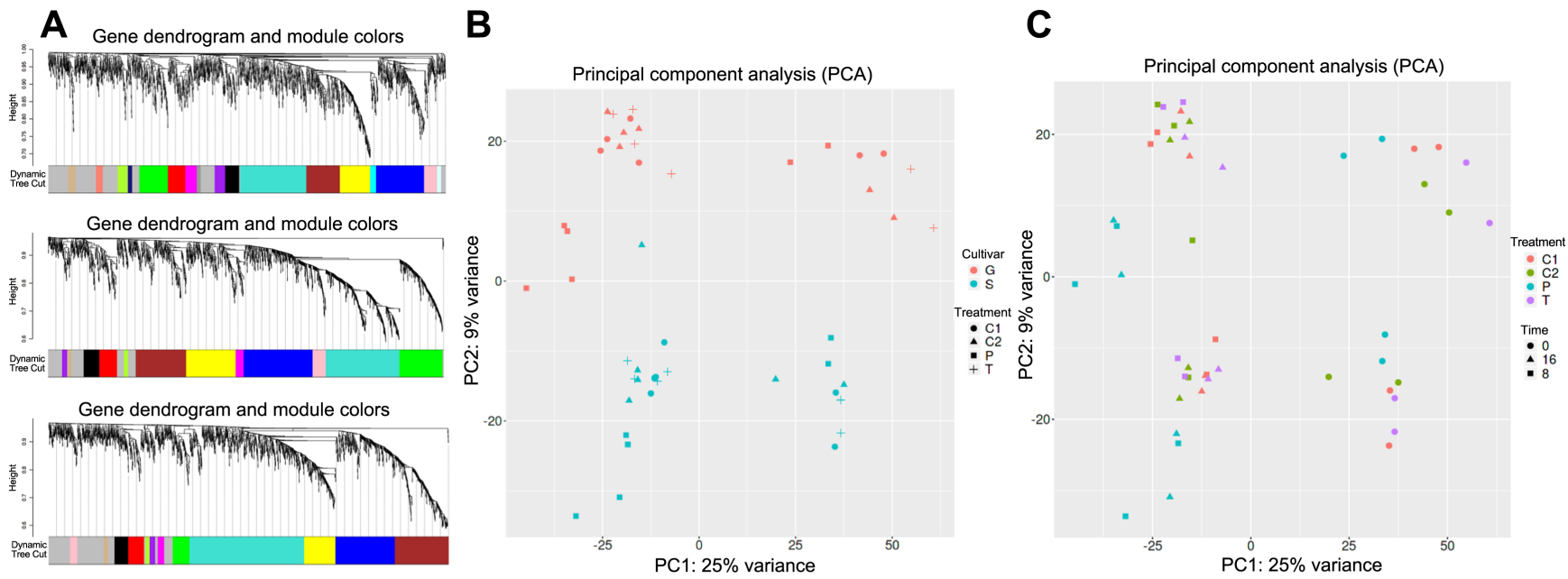

D

\begin{tabular}{|c|c|c|c|c|c|c|c|c|}
\hline \multicolumn{3}{|r|}{$\mathrm{Oh}$} & \multicolumn{3}{|r|}{$8 \mathrm{~h}$} & \multicolumn{3}{|r|}{$16 \mathrm{~h}$} \\
\hline Adj. $P$-value & Genes & Pathways & Adj. $P$-value & Genes & Pathways & Adj. $P$-value & Genes & Pathways \\
\hline $2.40 \mathrm{E}-12$ & 18 & Photosynthesis & $6.20 \mathrm{E}-12$ & 34 & Carboxylic acid metabolic process & $1.80 \mathrm{E}-08$ & 18 & Photosynthesis \\
\hline $2.70 \mathrm{E}-11$ & 25 & Generation of precursor metabolites and energy & $1.90 \mathrm{E}-11$ & 42 & Small molecule metabolic process & $9.40 \mathrm{E}-08$ & 27 & Generation of precursor metabolites and energy \\
\hline $3.40 \mathrm{E}-11$ & 13 & Photosynthesis, light reaction & $3.80 \mathrm{E}-11$ & 30 & Drug metabolic process & $2.20 \mathrm{E}-07$ & 47 & Organonitrogen compound biosynthetic process \\
\hline $1.40 \mathrm{E}-07$ & 8 & Photosynthesis, light harvesting & $5.80 \mathrm{E}-11$ & 13 & Aromatic amino acid family metabolic process & $9.00 \mathrm{E}-07$ & 44 & Small molecule metabolic process \\
\hline $1.10 \mathrm{E}-06$ & 5 & Protein repair & $6.50 \mathrm{E}-10$ & 17 & Alpha-amino acid metabolic process & $3.90 \mathrm{E}-06$ & 42 & Response to stress \\
\hline $9.00 \mathrm{E}-05$ & 15 & Response to abiotic stimulus & $4.30 \mathrm{E}-09$ & 24 & Small molecule biosynthetic process & $8.50 \mathrm{E}-06$ & 31 & Organic acid metabolic process \\
\hline $8.40 \mathrm{E}-04$ & 3 & Photosystem II repair & $5.30 \mathrm{E}-09$ & 21 & Cellular amino acid metabolic process & $5.10 \mathrm{E}-05$ & 29 & Carboxylic acid metabolic process \\
\hline $8.40 \mathrm{E}-04$ & 5 & Protein-chromophore linkage & $8.70 \mathrm{E}-09$ & 21 & Organic acid biosynthetic process & $5.70 \mathrm{E}-05$ & 20 & Response to abiotic stimulus \\
\hline $8.40 \mathrm{E}-04$ & 2 & Aldonate transmembrane transport & $3.10 \mathrm{E}-08$ & 32 & Catabolic process & $6.90 \mathrm{E}-05$ & 16 & Electron transport chain \\
\hline $8.40 \mathrm{E}-04$ & 6 & Chloroplast organization & 4.20E-08 & 23 & Cofactor metabolic process & $1.10 \mathrm{E}-04$ & 9 & Photosynthesis, light reaction \\
\hline $1.00 \mathrm{E}-03$ & 3 & Response to red light & $5.30 \mathrm{E}-08$ & 18 & Drug catabolic process & $2.90 \mathrm{E}-04$ & 15 & Cellular carbohydrate metabolic process \\
\hline $1.00 \mathrm{E}-03$ & 8 & Response to light stimulus & $1.70 \mathrm{E}-07$ & 34 & Response to stress & 3.10E-04 & 18 & Cellular amino acid metabolic process \\
\hline & & & & & & $3.10 \mathrm{E}-04$ & 11 & Purine nucleoside monophosphate metabc \\
\hline
\end{tabular}

Fig. 4. Analysis of expression data, including Weighted Correlation Network Analysis (WGCNA) of the three timepoints (0, 8 , and 16 h) (A); principal component analysis comparing the two cultivars with respect to treatment (B); principal component analysis comparing treatment and timepoint $(\mathrm{C})$; and functional pathways $(\mathrm{D})$ in which genes from 0,8 , and $16 \mathrm{~h}$ were associated as determined from the WGCNA. G, Glenlea; S, Salamouni; C1, control 1; C2, control 2; P, pathogen; and T, toxin.

genes in wheat: 6,340 genes between cultivars, 629 genes between treatments and 30,277 between timepoints (adjusted $P$-value $<0.05)$. These are visualized in the heat map (Fig. 3) where many genes either increased or decreased in expression, shown in red and green, respectively. The Weighted Correlation Network Analysis (WGCNA) and principal component analysis (PCA) of the data (Fig. 4AD) visually depicts the differences in expression between the cultivars and timepoints. Wheat samples at 8 and $16 \mathrm{~h}$ expressed many genes associated with response to stress and biosynthetic processes not expressed at $0 \mathrm{~h}$ (Supplementary Table 1).

Resistant and susceptible cultivar-specific gene expression. There were 6,340 genes that were differentially expressed between Glenlea and Salamouni wheat across the different timepoints and treatments (Supplementary Table 1), with many possessing potential involvement in defense response (Fig. 5). Several of these genes that were expressed highly in either Glenlea or Salamouni were expressed not at all or only slightly in the other cultivar (Fig.
5). For example, TraesCS5B02G417500.1 encodes an NBARC-containing protein and hundreds of reads from each of the Salamouni samples mapped to this gene, whereas not a single read was found in all Glenlea samples. For genes that are not expressed at all in one of the two cultivars, questions can be raised about if that cultivar even contains a functional version of that gene. Other genes were only associated with a single read in one cultivar. This could be a false positive. Groups of genes that are differentially expressed between the two cultivars, in general, either (1) had almost all of the genes of that type (e.g., chitinase) expressed in one cultivar (shown in Fig. 5), or (2) had a group of that type (e.g., nucleotide-binding and leucine-rich repeat [NLRs]) expressed in one cultivar and another group expressed in the other cultivar. This indicates that the two cultivars were using different genes of the same functional group to respond to the pathogen, with potentially different efficacy.

Glenlea and Salamouni do not show the same expression of chitinase/chitin-binding, major sperm protein, mildew resistance locus $\mathrm{O}$ (MLO), permease, ubiquitin, wall-as- 


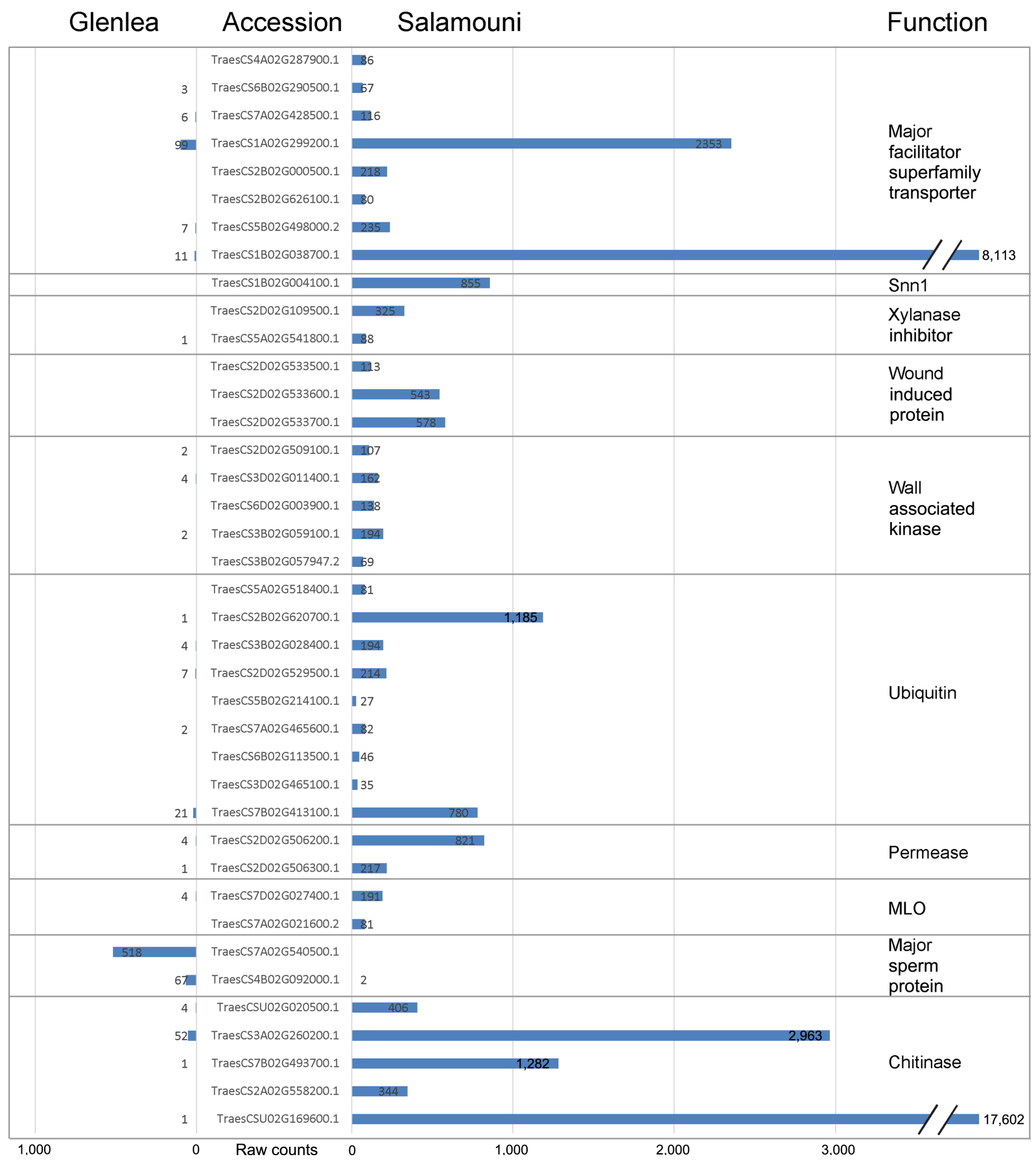

Fig. 5. Overall raw gene expression read counts between selected genes in Glenlea and Salamouni cutivars. Several genes were only expressed in Glenlea or Salamouni, with a few more showing only one read in one of the two cultivars.

sociated kinase (WAK), wound-induced, and xylanase inhibitors (Fig. 5). Each of these, with the exception of major sperm protein, were expressed almost exclusively in Salamouni. Salamouni also expressed a homolog of Snn1 (Fig. 5), which is a SnTox1 sensitivity gene that contains the domains of a calcium-binding and galacturonan-binding WAK. While many genes were only expressed in Glenlea, groups of genes with similar domains were not exclusively expressed in Glenlea like they were in Salamouni (Fig. 5). Glenlea and Salamouni express different NLRs, kinases, leucine-rich repeats (LRRs), LRR-kinases, cytochrome P450 enzymes, F-box proteins, lectins, peptidases, peptidase inhibitors, peroxidases, UDP-glucosyltransferases, thaumatins, and transcription factors. For these genes, 


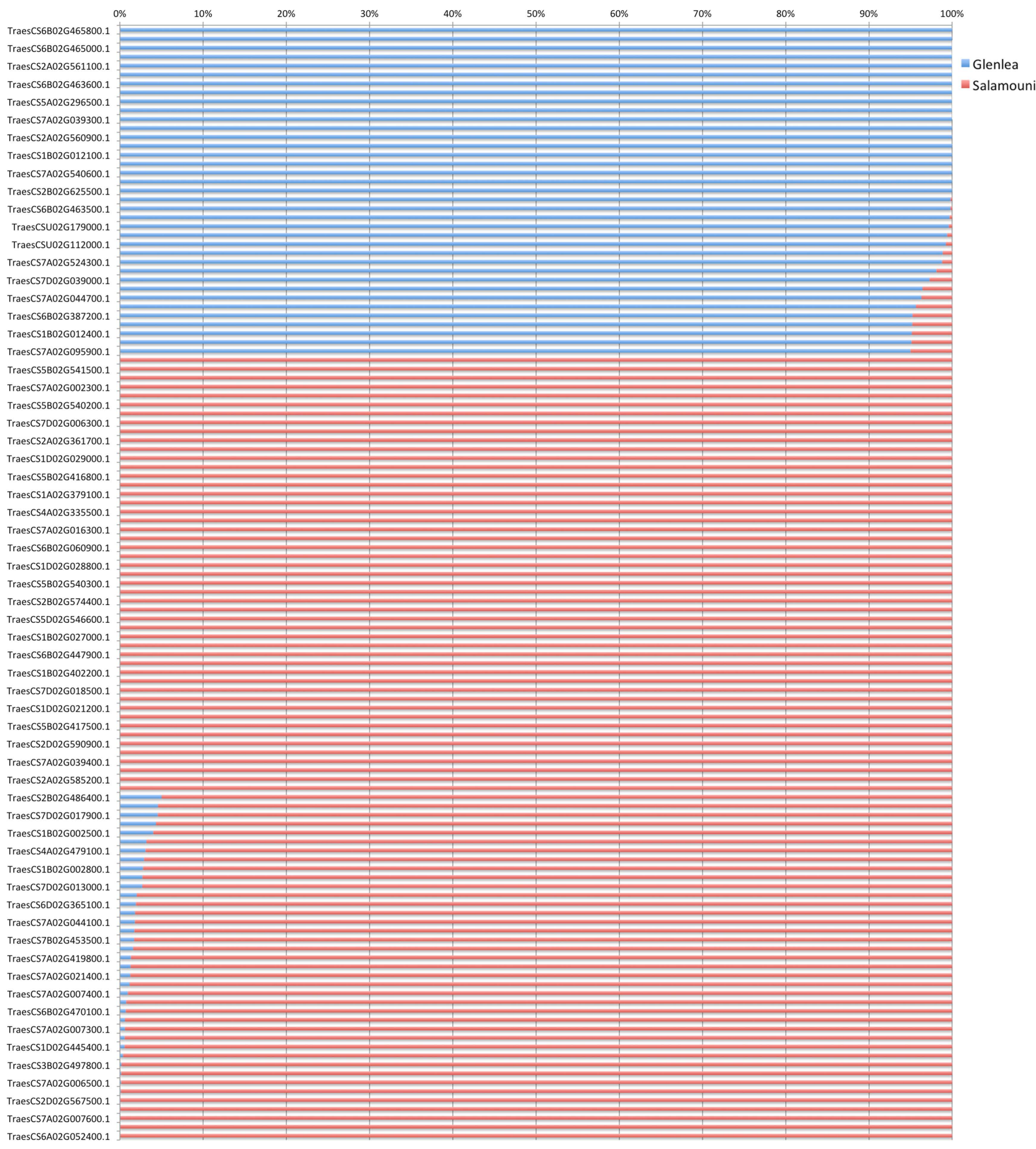

Fig. 6. Nucleotide-binding and leucine-rich repeat (NLR)-encoding genes that were differentially expressed between cultivars among all samples. NLR accession names are listed on the left and the proportion of reads found in either of the two cultivars are shown to the right of each name. Glenlea and Salamouni expression data are indicated by blue and red lines, respectively.

expression was seen exclusively or almost exclusively in either Glenlea or Salamouni, indicating that further research could target those only expressed in Salamouni. We acknowledge that our analyses focused on the genes that possess functions associated with pathogen resistance, not including the many other genes differentially expressed 


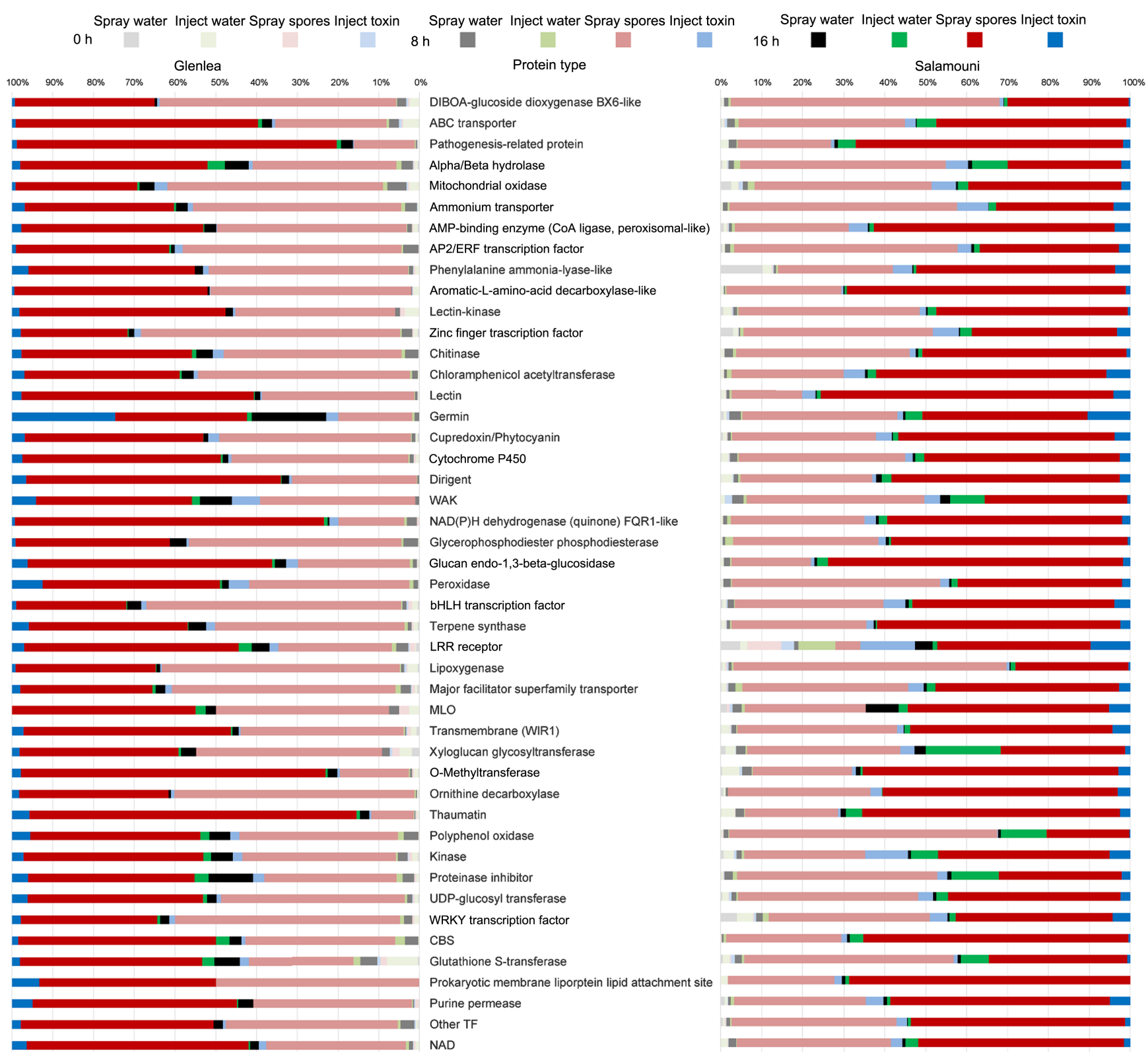

Fig. 7. Defense response genes that were differentially expressed highly when exposed to Pyrenophora tritici-repentis (Ptr) or ToxA, but minimally in $0 \mathrm{~h}$ samples and other control samples. Ptr triggered expression of several genes that were minimally expressed at 0 h, regardless of treatment. Grey, green, red, and blue indicate control inoculation, control infiltration, Ptr inoculation, and Ptr ToxA infiltration, respectively, as shown in the legend at the top of the figure. AP2/ERF, APETALA2/ethylene responsive factor; WAK, wallassociated kinase; LRR, leucine-rich repeat; MLO, mildew resistance locus O; TF, transcription factor; NAD, nicotinamide adenine dinucleotide.

between the cultivars that do not have possible resistance functions.

Of the differentially expressed genes, 125 NLRs were expressed mostly or entirely in one of the two cultivars (Fig. 6). Unlike genes listed in Fig. 5, where all or most of the genes of one type were expressed by one cultivar, NLRs were divided in expression between the two cultivars, with many expressed exclusively in one cultivar. Salamouni did show expression of more NLRs than Glenlea. However, the number of NLR-encoding genes expressed does not necessarily correlate with resistance, especially since it is not currently possible to associate individual NLRs with resistance to particular pathogens on a large scale. 


\begin{tabular}{lcccc}
\hline Domains & $1 \mathrm{~A}$ & $2 \mathrm{D}$ & $3 \mathrm{~B}$ & $5 \mathrm{~A}$ \\
\hline Alpha/Beta hydrolase & 2 & 6 & 2 & 1 \\
AP2/ERF transcription factor & 1 & 2 & 2 & - \\
bHLH transcription factor & - & 2 & - & 1 \\
Cullin repeat/Exocyst complex Exo70 & - & 4 & - & - \\
Cytochrome P450 & 1 & 5 & 2 & 1 \\
EGF calcium-binding/Kinase $\nabla$ & 1 & 2 & - & - \\
F-box/LRR & 5 & - & - & - \\
Haem peroxidase & - & 7 & 2 & - \\
Jacalin-like Lectin & - & - & 1 & - \\
Kinase & 3 & 14 & 2 & 5 \\
Lectin/Kinase $\nabla$ & 4 & 6 & 1 & - \\
LRR & 4 & 1 & 4 & 1 \\
LRR-Kinase & 6 & 6 & - & - \\
Major facilitator superfamily (transporter) & - & 2 & - & 2 \\
NAC transcription factor $\nabla$ & - & 4 & - & - \\
NB-ARC/CC & 3 & 2 & 3 & - \\
NLR & 8 & 5 & 1 & - \\
Thaumatin-like & - & - & - & 1 \\
Thioredoxin & - & 3 & - & - \\
UDP-glucosyltransferase & 2 & - & 9 & - \\
WRKY transcription factor $\nabla$ & - & 1 & 2 & - \\
Zinc finger & 6 & 10 & 5 & 5 \\
\hline
\end{tabular}

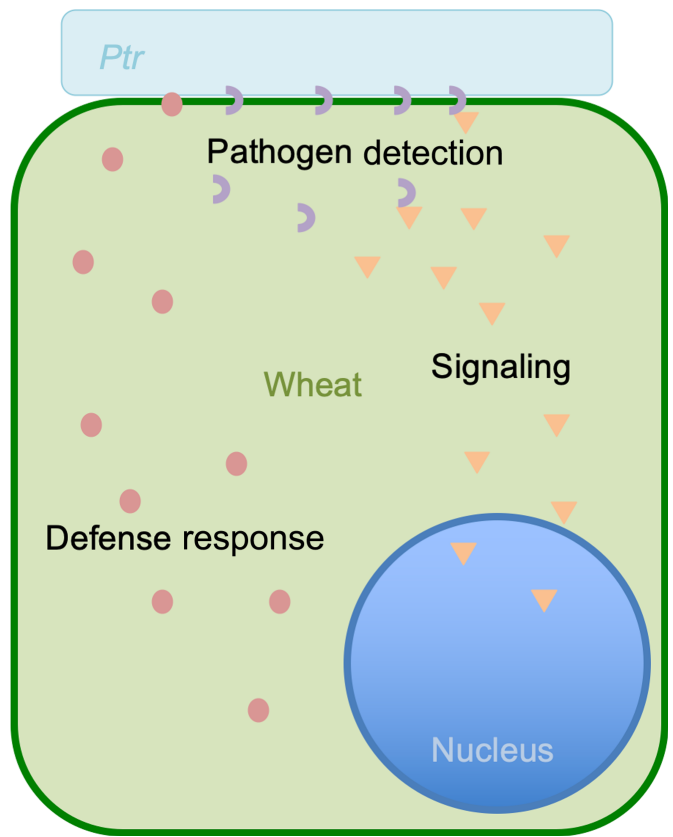

Fig. 8. Differentially expressed genes located within QTLs associated with resistance to tan spot, as described in Kariyawasam et al. (2016), and their proposed biological function. Functions are grouped by the following categories: pathogen detection (purple arcs), signaling (orange triangles), and defense response (red ovals).

Gene expression related to pathogen inoculation and toxin infiltration. Many groups of genes were expressed in both cultivars but differed greatly between control samples and those treated with Ptr inoculum or ToxA (see Fig. 7 gene groups). While this figure also highlights some differences between the two cultivars, the primary focus of this data was the differences between treatments with similar patterns in both cultivars. Many genes expressed much more in samples treated with Ptr inoculum that were not highly expressed in controls or ToxA infiltrated samples (Fig. 7). These included osmotin/thaumatin-like genes (e.g., TraesCS7B02G483400.1, TraesCS7D02G551400.1, and TraesCS7A02G558500.1) and cell wall synthesis genes such as TraesCS2B02G040600.1 and TraesCS2B02G040500.1, both of which are associated with disease resistance. Other genes (see Fig. 7) were expressed minimally or not at all in $0 \mathrm{~h}$ samples and controls at $8 \mathrm{~h}$, but highly expressed in $8 \mathrm{~h}$ pathogen or toxin exposure (Fig. 7). These genes are likely expressed in response to Ptr or ToxA. Several genes (e.g., TraesCS2B02G553700.1, TraesCS6B02G170000.1, and TraesCS7D02G058600.1) showed differential expression between treatments and cultivars, but did not share homology with any characterized genes, nor did they possess InterProScan domains. These genes are likely to play a role in pathogenesis, therefore their functional characterization is warranted, and many were found in locations associated with QTLs that likely play a role in TS resistance (Fig. 8).

\section{Discussion}

Expression of multiple resistance components in wheat. While pathogens are known to trigger defense responses in plants, the genes expressed in this response are extremely diverse. Previous studies have assessed the transcriptome of wheat upon TS infection to assess this diversity (Moolhuijzen et al., 2018). Each pathogen-host interaction involves many different receptors, signaling factors, and components associated with defense response. The presence of ToxA RNA in 8 and $16 \mathrm{~h}$ samples indicates that Ptr race 2 produces Ptr ToxA after contact with wheat tissue (Fig. 2). Other Ptr genes were also identified that may possess involvement in pathogenesis. For example, elongation factor is likely initiated once contact with wheat is sensed, along with peroxisomal enzymes. Proteins related to damage, such as heat shock proteins, could be expressed in response to enzymes wheat uses to defend itself during infection. Even though race 2 does not produce ToxB and ToxC, other factors likely elicit response to Ptr, such as chitin and other pathogen-associated molecular patterns (PAMPs) (Jones and Dangl, 2006). PAMPs and break down of the plant cell wall by fungal enzymes trigger the activation of pattern-recognition receptors (PRRs) and WAKs, respectively (Bacete et al., 2018). PRRs generally possess LRR 
and kinase domains, with an extracellular LRR initiating intracellular kinase activity (Bacete et al., 2018). WAKs possess galacturonan-binding domains and kinase domains, with kinase activity initiated by cell wall fragments. Several kinases, including LRR-kinases and WAKs, were expressed more highly in plants sprayed with inoculum or injected with the toxin. Kinases then phosphorylate additional signaling molecules, eventually triggering transcription factor activation. Several transcription factors were expressed more highly when exposed to the pathogen. Expression of transcription factors of the AP2/ERF, bHLH, and WRKY classes were triggered by Ptr. While further functional characterization is required to know how these kinases and transcription factors are directly involved in response to Ptr, this analysis highlights which signaling factors may be involved. These kinases and transcription factors would not necessarily be the same signaling factors initiated by receptor detection of Ptr, since RNA-seq only measures changes in expression. These would be the kinases and transcription factors that are expressed as the result of initial receptor/signaling activity. Therefore, the initial detection is not captured in this experiment, only the genes expressed as a result of the initial detection of Ptr. As a direct result of pathogen detection, the first line of defense detectable through RNA-seq would be the defense response genes expressed more highly in the hours following inoculation. The heatmap (Fig. 3), shows that many genes increased or decreased in expression through the course of the experiment with many genes differing between the two cultivars, as shown in the PCA (Fig. 4B and C). The WGCNA (Fig. 4A and D) shows that many genes expressed at 8 and $16 \mathrm{~h}$ may play roles in defense, particularly those in the pathways associated with stress response (34 and 42 genes at 8 and $16 \mathrm{~h}$, respectively), small molecule metabolic process (42 and 44 genes), and small molecule biosynthesis process ( 24 at $8 \mathrm{~h})$.

Differences between resistant and susceptible wheat. Many genes identified in this study possess direct resistance functions in response to Ptr, such as chitinases, thaumatins, terpene synthases, purine permeases, and peroxidases. Each of these likely functions in the breakdown of pathogen components or the production of compounds that deter pathogen growth and development. Chitinases, for example, break down chitin in fungal cell walls and inhibit fungal development and reproduction. Chitinases were expressed more by Salamouni than by Glenlea (Fig. 5). Given that Ptr is a fungal pathogen, this production of chitinase may play a significant role in the resistance Salamouni possesses. WAK-encoding genes were also found to be expressed more in Salamouni, possibly initiating defense responses when damage to the cell wall takes place. In a similar study of the wheat-Ptr system, Pandelova et al. (2009) also found differential expression of several signaling genes (i.e., mitogen-activated protein kinases and transcription factors) along with response protein-encoding genes like chitinase (Pandelova et al., 2009). NLRs, commonly described as major resistance factors, were largely or entirely either expressed in one cultivar or the other, with the majority of them expressed in Salamouni (Fig. 6). This data indicates that cultivars do not equally express NLRs. While this does show differences between the two cultivars, RNA-seq likely cannot capture the overall interaction, only those genes that are up-regulated or down-regulated. For example, pathogen-detecting receptors unique to one cultivar or another would not show up in this analysis if they were not up-regulated after the resistance response was triggered.

Ptr associated chemical defense. Thuamatin-like proteins are permatins that make the fungal membranes more permeable, disrupting cellular activity. These defensive proteins were among the many types that expressed more highly in plants inoculated with Ptr spores (Fig. 7). Other enzymes do not directly act against fungal cells but catalyze the production of chemicals that inhibit fungal development. Benzoxazinoids, such as DIMBOA, are produced as a defense against pests and are synthesized through the activity of several BX enzymes (Frey et al., 2009). BX1 catalyzes the production of indole from indole3-glycerolphosphate. Cytochrome P450 enzymes Bx2Bx5 convert indole to DIBOA. BX6 catalyzes DIBOAglucoside into TRIBOA-glucoside, which then is acted upon by BX7, converting it to DIMBOA-glucoside, the main benzoxazinoid for wheat (Frey et al., 2009). UDPglucosyltrasferases like $\mathrm{Bx} 8$ and $\mathrm{Bx} 9$ reduce autotoxicity of benzoxazinoids. This data indicates that several Cytochome P450, DIBOA-glucoside dioxygenase (BX6)-like, and UDP-glucosyltransferase proteins were more heavily expressed in race 2-inoculated samples. Since DIMBOA is known to possess antifungal properties, up-regulation of enzymes in its synthetic pathway fit expectations. Indole3-glycerolphosphate can be converted into either DIMBOA-glucoside or tryptophan, with DIMBOA-glucoside then being coverted to 6-methoxy-2-benzoxazolinone (MBOA) and tryptophan being converted into serotonin. Du Fall and Solomon (2013) showed that in response to SnToxA from Stagonospora nodorum, wheat produces secondary metabolites serotonin and MBOA to inhibit $S$. nodorum sporulation and disrupt metabolism, respectively 
(Du Fall and Solomon, 2013). Therefore, the up-regulation of DIMBOA pathway enzymes may be to use serotonin and MBOA to inhibit Ptr. Du Fall and Solomon (2013) suggest that $S$. nodorum uses other effectors to suppress the response triggered by SnToxA.

Response proteins may work together in other ways to defend wheat from Ptr infection. Four groups of genes uniquely expressed in race 2-inoculated samples share a common defense pathway: UDP-glucosyltransferases, cytochrome P450s, beta-glucosidases, and alpha/beta hydrolases. These proteins lead to the production of hydrogen cyanide as a defense mechanism in Sorghum bicolor. The cyanogenic glucoside dhurrin is synthesized by UDP-glucosyltransferase and cytochrome P450. Dhurrinase, a betaglucosidase, releases p-hydroxymandelonitrile from dhurrin, which is acted upon by $\mathrm{p}-(\mathrm{S})$-hydroxymandelonitrile lyase, an alpha/beta hydrolase, to make hydrogen cyanide (Ordonio et al., 2016). Like S. bicolor, wheat also produces cyanogenic glucosides (Bak et al., 2006). Genes encoding all four of these proteins were expressed more highly in samples inoculated with Ptr than other samples.

Many of the genes expressed more highly when wheat was exposed to Ptr inoculum possess additional functions in resistance systems. Pyridoxal phosphate-dependent decarboxylases (aromatic-L-amino-acid decarboxylases) (Fig. 7) were differentially expressed and play roles in $\gamma$-aminobutyric acid (GABA) signaling. Wang et al. (2018) have proposed a self-defense model in Fusarium graminearum, where major facilitator superfamily transporters export deoxynivalenol (DON) and GABA promotes production of DON as a self-defense. Inoculation with the pathogen may have triggered this due to the presence of PAMPs, whereas toxin infiltration would have bypassed this response. Proteinase inhibitors, also shown in Fig. 7, were also identified in this study and likely counter Ptr proteins that degrade the plant's barriers to infection, such as the cell wall. Polyphenol oxidases (Fig. 7) are defense compounds known to reduce the digestibility of plant tissue. Phenylalanine ammonia-lyase is another common defense protein plants use. Wheat dirigents (Fig. 7) have been shown to increase pathogen resistance and lignin biosynthesis (Ma and Liu, 2015), which would be used to made infection more difficult. Ornithine decarboxylase catalyzes the conversion of ornithine to putrescine, which can then be converted to spermidine and spermine, a response to biotic stress caused by a broad range of pathogens (Dalton et al., 2016). Lipoxygenases (Fig. 7) aid in the synthesis of signaling molecules, such as jasmonates, which are important signaling factors in defense responses (Woldemariam et al., 2018). Signaling and response genes that were found to be mostly expressed in the samples inoculated with $P$ tr race 2 indicate that $P t r$ is initiating responses based upon receptor activity. Several lectins, lectin-kinases, kinases, and LRR receptors were mainly expressed in race 2-inoculated samples. These proteins likely work together to transmit the signal that the fungal pathogen is present. The expression of several transcription factors commonly associated with biotic stress resistance was triggered by inoculation by Ptr.

QTLs associated with resistance components. Additional research targeting TS has associated Ptr resistance with various QTLs throughout the wheat genome. Kariyawasam et al. (2016) identified QTLs involved in TS resistance (Kariyawasam et al., 2016) and further work has been done since identifying Meta-QTLs (Liu et al., 2020). While cultivar Penawawa is resistant to several races of Ptr, application of ToxA causes necrosis, the same reaction found in the susceptible cultivar Louise. One major QTL associated with non-race-specific resistance exists on the long arm of chromosome 3B, called QTs.zhl-3B, which may be the same as $Q T s . f c u-3 B L$ (Faris and Friesen, 2005), similar in location to other genes associated with TS resistance (tsr2 and $t s r 5$ ). Additional QTLs were found on chromosomes $1 \mathrm{~A}, 2 \mathrm{D}$, and $5 \mathrm{~A}$, the latter conferring resistance to all tested races of Ptr (Kariyawasam et al., 2016). Many differentially expressed genes have locations within these QTLs (Fig. 8). Several of these genes possess possible roles in resistance, either as receptors (NLRs, other LRRcontaining receptors), signal transduction factors (kinases, transcription factors), or response proteins (peroxidases, hydrolases). The genes found within these QTLs represent the same types of genes discussed in the previous sections, those that differ in expression between cultivars and inoculation treatments.

Ptr isolate 86-124 penetrates wheat tissue within $3 \mathrm{~h}$ after inoculation and continues infection in the hours following (Dushnicky et al., 1996), indicating that the $8 \mathrm{~h}$ time point provides a view of expression after Ptr has had a chance to initiate the expression of defense genes. The humidity chamber provided the moisture required for Ptr infection. Ptr uses an appressorium and penetration peg to access wheat epidermal cells (Larez et al., 1986). Both resistant and susceptible host plants experience penetration (Larez et al., 1986), explaining why many similarities may exist between the two cultivars in expression. If Ptr was not able to penetrate the resistant cultivar, more diverse expression may have resulted. Since $8 \mathrm{~h}$ after inoculation shows wheat responding to Ptr through the production of defense proteins and chemicals, it is likely that some of the genes expressed by Ptr at this point are also in response to wheat. 
Gene expression in a pathogen changes in response to the host just as the host changes gene expression after the pathogen has been detected. Some of the stress-response genes expressed by Ptr, such as those listed in Fig. 2, are likely involved in responding to wheat defense mechanisms.

Future directions. Wheat lines with the specific susceptibility genes $T s n 1, T s c 2$, and $T s c 1$ are vulnerable to Ptr ToxA, Ptr ToxB, and Ptr ToxC, respectively (Faris et al., 2013). Wheat lines with the mutant alleles $t s n 1$, tsc 2 , and tscl are not sensitive to the respective toxins (Cheong et al., 2004; Effertz et al., 2002; Friesen and Faris, 2004), indicating that susceptibility genes play a major role in TS infection. Liu et al. (2017) used recombinant inbred lines with various combinations of homozygous dominant, heterozygous, and homozygous recessive genotypes of $T s n 1$ and $T s c 1$, to show that the plants that lack the $t s n 1$ and $t s c 1$ alleles experienced toxin-induced necrosis and chlorosis, respectively (Liu et al., 2017). It is not completely understood how these susceptibility genes cause wheat lines to be sensitive to particular toxins or effectors. Similar to the Cochliobolus victoriae susceptibility gene LOV1 in Arabidopsis thaliana (Lorang et al., 2007), Tsn1 encodes a cytoplasmic NBS-LRR protein, belonging to a large family of R-proteins that generally function as cytoplasmic receptors for the detection of pathogenic effectors. The recently available nucleotide and protein sequences of $T s n 1$ and Tsn1, respectively, suggest that $T s n 1$ is the result of a gene-fusion that took place in the progenitor of wheat's Bgenome, a close relative of Aegilops speltoides (Faris et al., 2010). Early analysis of TS described the Ptr toxins as necessary for the development of disease symptoms, however, a recent study has confirmed that even non-toxin-producing Ptr races still cause necrosis and chlorosis (Ali et al., 2010). Wheat cultivars may even show necrosis when inoculated with Ptr races that only produce Ptr ToxB (Lamari et al., 1998). Taken together, these details show that both Ptr virulence and wheat resistance are multifaceted.

Conclusions. Ptr provides a complex example of a pathogen that has evolved the ability to hijack resistance components to cause infection. The presence of ToxA RNA in 8- and 16-h samples indicated that, upon Ptr contact with wheat tissue, Ptr started expressing ToxA. Wheat, in response to Ptr inoculum, expresses many genes associated with plant resistance responses, including chitinases, transporters, pathogen-detecting receptors, and signaling factors. Resistant and susceptible wheat cultivars differed in expression between several groups of genes (genes that encode chitinases, transporters, WAKs, permeases, and wound-induced proteins, etc.). Plants exposed to Ptr inoculum expressed several groups of genes not expressed as highly in control samples, such as transcription factors, kinases, receptors, and peroxidases. Several of the differentially expressed genes can be found in TS resistance QTLs on chromosomes 1A, 2D, 3B, and 5A. These results show that resistance to Ptr is likely the result of many individual genes being expressed. Elucidating genes involved in resistance to Ptr will provide researchers and breeders specific target factors for developing cultivars that possess these components, with the goal of establishing durable Ptr resistance. Gaining a more complete molecular picture of Ptr infection may also elucidate why Ptr has become a major disease of wheat in recent years. Future studies should seek to focus in on these specific groups of genes to isolate particular roles that they play in the wheat-Ptr interaction.

\section{Conflicts of Interest}

No potential conflict of interest relevant to this article was reported.

\section{Acknowledgments}

Support for this project came from the USDA-NIFA hatch Projects to M. Nepal (SD00H469-13 and SD00H659-18), South Dakota Agriculture Experiment Station, and Department of Biology \& Microbiology at South Dakota State University. The authors would also like to thank Timothy Friesen for supplying Ptr ToxA solution.

\section{Electronic Supplementary Material}

Supplementary materials are available at The Plant Pathology Journal website (http://www.ppjonline.org/).

\section{References}

Abdullah, S., Sehgal, S. K., Ali, S., Liatukas, Z., Ittu, M. and Kaur, N. 2017. Characterization of Pyrenophora tritici-repentis (tan spot of wheat) races in Baltic States and Romania. Plant Pathol. J. 33:133-139.

Adhikari, T. B., Bai, J., Meinhardt, S. W., Gurung, S., Myrfield, M., Patel, J., Ali, S., Gudmestad, N. C. and Rasmussen, J. B. 2009. Tsn1-mediated host responses to ToxA from $P y$ renophora tritici-repentis. Mol. Plant-Microbe Interact. 22:1056-1068.

Ali, S. and Francl, L. J. 2001. Recovery of Pyrenophora triticirepentis from barley and reaction of 12 cultivars to five races and two host-specific toxins. Plant Dis. 85:580-584. 
Ali, S. and Francl, L. J. 2003. Population race structure of $P y$ renophora tritici-repentis prevalent on wheat and noncereal grasses in the great plains. Plant Dis. 87:418-422.

Ali, S., Gurung, S. and Adhikari, T. B. 2010. Identification and characterization of novel isolates of Pyrenophora triticirepentis from Arkansas. Plant Dis. 94:229-235.

Altschul, S. F., Gish, W., Miller, W., Myers, E. W. and Lipman, D. J. 1990. Basic local alignment search tool. J. Mol. Biol. 215:403-410.

Anders, S., Pyl, P. T. and Huber, W. 2015. HTSeq: a Python framework to work with high-throughput sequencing data. Bioinformatics 31:166-169.

Andersen, E. J., Ali, S. and Nepal, M. P. 2019a. Supplementary files for transcriptomic changes in wheat during tan spot (pyrenophora tritici-repentis) disease. Sequence Read Archive, SRP189899. URL https://identifiers.org/ncbi/insdc. sra:SRP189899 [28 January 2021].

Andersen, E. J., Ali, S. and Nepal, M. P. 2019b. Transcriptomic changes in wheat during tan spot (Pyrenophora tritici-repentis) disease. BMC Res. Notes 12:471.

Andrews, S. 2010. FastQC: a quality control tool for high throughput sequence data. URL http://www.bioinformatics. babraham.ac.uk/projects/fastqc/ [28 January 2021].

Bacete, L., Mélida, H., Miedes, E. and Molina, A. 2018. Plant cell wall-mediated immunity: cell wall changes trigger disease resistance responses. Plant J. 93:614-636.

Bak, S., Paquette, S. M., Morant, M., Morant, A.V., Saito, S., Bjarnholt, N., Zagrobelny, M., Jørgensen, K., Osmani, S., Simonsen, H. T., Pérez, R. S., van Heeswijck, T. B., Jørgensen, B. and Møller, B. L. 2006. Cyanogenic glycosides: a case study for evolution and application of cytochromes P450. Phytochem. Rev. 5:309-329.

Cheong, J., Wallwork, H. and Williams, K. 2004. Identification of a major QTL for yellow leaf spot resistance in the wheat varieties Brookton and Cranbrook. Aust. J. Agric. Res. 55:315319.

Ciuffetti, L. M., Francl, L. J., Ballance, G. M., Bockus, W. W., Lamari, L., Meinhardt, S. W. and Rasmussen, J. B. 1998. Standardization of toxin nomenclature in the Pyrenophora tritici-repentis/wheat interaction. Can. J. Plant Pathol. 20:421-424.

Ciuffetti, L. M., Manning, V. A., Pandelova, I., Betts, M. F. and Martinez, J. P. 2010. Host-selective toxins, Ptr ToxA and Ptr ToxB, as necrotrophic effectors in the Pyrenophora triticirepentis-wheat interaction. New Phytol. 187:911-919.

Ciuffetti, L. M. and Tuori, R. P. 1999. Advances in the characterization of the Pyrenophora tritici-repentis-wheat interaction. Phytopathology 89:444-449.

Dalton, H. L., Blomstedt, C. K., Neale, A. D., Gleadow, R., DeBoer, K. D. and Hamill, J. D. 2016. Effects of down-regulating ornithine decarboxylase upon putrescine-associated metabolism and growth in Nicotiana tabacum L. J. Exp. Bot. 67:3367-3381.

Du Fall, L. A. and Solomon, P. S. 2013. The necrotrophic effec- tor SnToxA induces the synthesis of a novel phytoalexin in wheat. New Phytol. 200:185-200.

Dushnicky, L. G., Ballance, G. M., Sumner, M. J. and MacGregor, A. W. 1996. Penetration and infection of susceptible and resistant wheat cultivars by a necrosis toxin-producing isolate of Pyrenophora tritici-repentis. Can. J. Plant Pathol. 18:392-402.

Effertz, R. J., Meinhardt, S. W., Anderson, J. A., Jordahl, J. G. and Francl, L. J. 2002. Identification of a chlorosis-inducing toxin from Pyrenophora tritici-repentis and the chromosomal location of an insensitivity locus in wheat. Phytopathology 92:527-533.

Faris, J. D., Anderson, J. A., Francl, L. J. and Jordahl, J. G. 1996. Chromosomal location of a gene conditioning insensitivity in wheat to a necrosis-inducing culture filtrate from Pyrenophora tritici-repentis. Phytopathology 86:459-463.

Faris, J. D. and Friesen, T. L. 2005. Identification of quantitative trait loci for race-nonspecific resistance to tan spot in wheat. Theor. Appl. Genet. 111:386-392.

Faris, J. D., Liu, Z. and Xu, S. S. 2013. Genetics of tan spot resistance in wheat. Theor. Appl. Genet. 126:2197-2217.

Faris, J. D., Zhang, Z., Lu, H., Lu, S., Reddy, L., Cloutier, S., Fellers, J. P., Meinhardt, S. W., Rasmussen, J. B., Xu, S. S., Oliver, R. P., Simons, K. J. and Friesen, T. L. 2010. A unique wheat disease resistance-like gene governs effector-triggered susceptibility to necrotrophic pathogens. Proc. Natl. Acad. Sci. U. S. A. 107:13544-13549.

Figueroa, M., Manning, V. A., Pandelova, I. and Ciuffetti, L. M. 2015. Persistence of the host-selective toxin Ptr ToxB in the apoplast. Mol. Plant-Microbe Interact. 28:1082-1090.

Food and Agriculture Organization of the United Nations. 2013. FAOSTAT. URL http://www.fao.org/faostat/en/\#data [28 January 2021].

Frey, M., Schullehner, K., Dick, R., Fiesselmann, A. and Gierl, A. 2009. Benzoxazinoid biosynthesis, a model for evolution of secondary metabolic pathways in plants. Phytochemistry 70:1645-1651.

Friesen, T. L. and Faris, J. D. 2004. Molecular mapping of resistance to Pyrenophora tritici-repentis race 5 and sensitivity to Ptr ToxB in wheat. Theor. Appl. Genet. 109:464-471.

Friesen, T. L., Stukenbrock, E. H., Liu, Z., Meinhardt, S., Ling, H., Faris, J. D., Rasmussen, J. B., Solomon, P. S., McDonald, B. A. and Oliver, R. P. 2006. Emergence of a new disease as a result of interspecific virulence gene transfer. Nat. Genet. 38:953-956.

Ge, S. X., Son, E. W. and Yao, R. 2018. iDEP: an integrated web application for differential expression and pathway analysis of RNA-Seq data. BMC Bioinformatics 19:534.

International Wheat Genome Sequencing Consortium. 2018. Shifting the limits in wheat research and breeding using a fully annotated reference genome. Science 361:eaar7191.

Jones, J. D. and Dangl, J. L. 2006. The plant immune system. $N a$ ture 444:323-329.

Jones, P., Binns, D., Chang, H.-Y., Fraser, M., Li, W., McAnulla, 
C., McWilliam, H., Maslen, J., Mitchell, A., Nuka, G., Pesseat, S., Quinn, A. F., Sangrador-Vegas, A., Scheremetjew, M., Yong, S.-Y., Lopez, R. and Hunter, S. 2014. InterProScan 5: genome-scale protein function classification. Bioinformatics 30:1236-1240.

Jordahl, J. G. and Francl, L. J. 1992. Increase and storage of cultures of Pyrenophora tritici-repentis. In: Advances in Tan Spot Research: Proceedings of the Second International Tan Spot Workshop, eds. by L. J. Francl, J. M. Krupinsky and M. P. McMullen, pp. 109. North Dakota Agricultural Experiment Station, North Dakota State University, Fargo, ND, USA.

Kariyawasam, G. K., Carter, A. H., Rasmussen, J. B., Faris, J., $\mathrm{Xu}, \mathrm{S}$. S., Mergoum, M. and Liu, Z. 2016. Genetic relationships between race-nonspecific and race-specific interactions in the wheat-Pyrenophora tritici-repentis pathosystem. Theor. Appl. Genet. 129:897-908.

Kersey, P. J., Allen, J. E., Christensen, M., Davis, P., Falin, L. J., Grabmueller, C., Hughes, D. S., Humphrey, J., Kerhornou, A., Khobova, J., Langridge, N., McDowall, M. D., Maheswari, U., Maslen, G., Nuhn, M., Ong, C. K., Paulini, M., Pedro, H., Toneva, I., Tuli, M. A., Walts, B., Williams, G., Wilson, D., Youens-Clark, K., Monaco, M. K., Stein, J., Wei, X., Ware, D., Bolser, D. M., Howe, K. L., Kulesha, E., Lawson, D. and Staines, D. M. 2014. Ensembl genomes 2013: scaling up access to genome-wide data. Nucleic Acids Res. 42:D546-D552.

Kim, D., Langmead, B. and Salzberg, S. L. 2015. HISAT: a fast spliced aligner with low memory requirements. Nat. Methods 12:357-360.

Kong, Y. 2011. Btrim: a fast, lightweight adapter and quality trimming program for next-generation sequencing technologies. Genomics 98:152-153.

Lamari, L. and Bernier, C. C. 1989. Evaluation of wheat lines and cultivars to tan spot Pyrenophora tritici-repentis based on lesion type. Can. J. Plant Pathol. 11:49-56.

Lamari, L., Gilbert, J. and Tekauz, A. 1998. Race differentiation in Pyrenophora tritici-repentis and survey of physiologic variation in western Canada. Can. J. Plant Pathol. 20:396400.

Larez, C. R., Hosford, R. M. Jr. and Freeman, T. P. 1986. Infection of wheat and oats by Pyrenophora tritici-repentis and initial characterization of resistance. Phytopathology 76:931938.

Liu, Y., Salsman, E., Wang, R., Galagedara, N., Zhang, Q., Fiedler, J. D., Liu, Z., Xu, S., Faris, J. D. and Li, X. 2020. Meta-QTL analysis of tan spot resistance in wheat. Theor. Appl. Genet. 133:2363-2375.

Liu, Z., Zurn, J. D., Kariyawasam, G., Faris, J. D., Shi, G., Hansen, J., Rasmussen, J. B. and Acevedo, M. 2017. Inverse gene-for-gene interactions contribute additively to tan spot susceptibility in wheat. Theor. Appl. Genet. 130:1267-1276.

Lorang, J. M., Sweat, T. A. and Wolpert, T. J. 2007. Plant disease susceptibility conferred by a "resistance" gene. Proc. Natl. Acad. Sci. U. S. A. 104:14861-14866.

Love, M. I., Huber, W. and Anders, S. 2014. Moderated estima- tion of fold change and dispersion for RNA-seq data with DESeq2. Genome Biol. 15:550.

Ma, Q.-H. and Liu, Y.-C. 2015. TaDIR13, a dirigent protein from wheat, promotes lignan biosynthesis and enhances pathogen resistance. Plant Mol. Biol. Rep. 33:143-152.

Manning, V. A., Chu, A. L., Steeves, J. E., Wolpert, T. J. and Ciuffetti, L. M. 2009. A host-selective toxin of Pyrenophora tritici-repentis, Ptr ToxA, induces photosystem changes and reactive oxygen species accumulation in sensitive wheat. Mol. Plant-Microbe Interact. 22:665-676.

Manning, V. A., Hamilton, S. M., Karplus, P. A. and Ciuffetti, L. M. 2008. The Arg-Gly-Asp-containing, solvent-exposed loop of Ptr ToxA is required for internalization. Mol. PlantMicrobe Interact. 21:315-325.

Manning, V. A., Hardison, L. K. and Ciuffetti, L. M. 2007. Ptr ToxA interacts with a chloroplast-localized protein. Mol. Plant-Microbe Interact. 20:168-177.

Moolhuijzen, P., See, P. T. and Moffat, C. S. 2018. Exploration of wheat and pathogen transcriptomes during tan spot infection. BMC Res. Notes 11:907.

Murray, T. D., Bockus, W. W., Bowden, R. L., Hunger, R. M. and Smiley, R. W. 2015. Diseases of wheat (Triticum spp. L.). URL https://www.apsnet.org/edcenter/resources/commonnames/Pages/Wheat.aspx [28 January 2021].

Ordonio, R., Ito, Y., Morinaka, Y., Sazuka, T. and Matsuoka, M. 2016. Molecular breeding of Sorghum bicolor, a novel energy crop. Int. Rev. Cell Mol. Biol. 321:221-257.

Pandelova, I., Betts, M. F., Manning, V. A., Wilhelm, L. J., Mockler, T. C. and Ciuffetti, L. M. 2009. Analysis of transcriptome changes induced by Ptr ToxA in wheat provides insights into the mechanisms of plant susceptibility. Mol. Plant 2:10671083.

Petrov, V., Qureshi, M. K., Hille, J. and Gechev, T. 2018. Occurrence, biochemistry and biological effects of host-selective plant mycotoxins. Food Chem. Toxicol. 112:251-264.

Rees, R. G. and Platz, G. J. 1983. Effects of yellow spot on wheat: comparison of epidemics at different stages of crop development. Aust. J. Agric. Res. 34:39-46.

Shi, G., Zhang, Z., Friesen, T. L., Raats, D., Fahima, T., Brueggeman, R. S., Lu, S., Trick, H. N., Liu, Z., Chao, W., Frenkel, Z., $\mathrm{Xu}$, S. S., Rasmussen, J. B. and Faris, J. D. 2016. The hijacking of a receptor kinase-driven pathway by a wheat fungal pathogen leads to disease. Sci. Adv. 2:e1600822.

Singh, R. P., Singh, P. K., Rutkoski, J., Hodson, D. P., He, X., Jørgensen, L. N., Hovmøller, M. S. and Huerta-Espino, J. 2016. Disease impact on wheat yield potential and prospects of genetic control. Annu. Rev. Phytopathol. 54:303-322.

Tai, Y.-S., Bragg, J., Lu, H., Edwards, M. C., Faris, J. D., Friesen, T. L. and Meinhardt, S. W. 2007. Functional characterization of Ptr ToxA and molecular identification of its intracellular targeting protein in wheat. In: Plant and Animal Genome XV Conference Abstracts, publication no. 201233. Scherago International, Livingston, NJ, USA.

The R Foundation. 2013. The R project for statistical computing. 
URL https://www.r-project.org/ [28 January 2021].

Wang, Q., Chen, D., Wu, M., Zhu, J., Jiang, C., Xu, J. R. and Liu, H. 2018. MFS transporters and GABA metabolism are involved in the self-defense against DON in Fusarium gra- minearum. Front. Plant Sci. 9:438.

Woldemariam, M. G., Ahern, K., Jander, G. and Tzin, V. 2018. A role for 9-lipoxygenases in maize defense against insect herbivory. Plant Signal. Behav. 13:e1422462. 